\title{
Noninvasive Detection of Specific Diagnostic Biomarkers for Atopic Dermatitis
}

\author{
Jeong Hyun Chang ${ }^{\dagger, *}$ \\ Department of Clinical Laboratory Science, Daegu Haany University, Gyeongsan-si 38610, Korea
}

\begin{abstract}
The diagnosis of atopic dermatitis (AD) includes a test that checks allergen-mediated skin reactions and a method of measuring the total IgE and allergen-specific IgE in blood. However, these test methods are performed directly on the patient, which cause some pain or discomfort. In addition, the skin response test or IgE may result in false negative in about $20 \%$ of patients. In the present study, to identify specific biomarkers, HaCaT cells were used as a human keratinocyte that make up the skin, were treated IL-4 and IL-13 for 24 hours to induce a situation similar to keratinocytes in AD patients. In the HaCaT cells, pro-inflammatory cytokine such as IL-5, IL-6, and MCP-1 were increased by IL-4 and IL-13 and skin barrier proteins was reduced by IL-4 and L-13. This results showed that a situation similar to the stratum corneum of an actual patient is induced in HaCaT cells. And then the secretions of Kallikrein (KLK) 5 and KLK7 protease were checked by enzyme-linked immunosorbent assay (ELISA). It was specifically increased by IL-4 and IL-13. This showed that $\mathrm{AD}$-related protease can be detected at the protein level using keratinocytes that can be taken in a non-invasive manner and suggested the possibility of applying it to AD diagnosis.
\end{abstract}

Key Words: Atopic dermatitis, Keratinocyte, Diagnosis, Kallikrein 5, Kallikrein 7

\section{INTRODUCTION}

As one of the representative advanced country diseases in a westernized and industrialized society, atopic dermatitis (AD) is a refractory immune disease and is steadily increasing. According to the result of the National Health and Nutrition Examination Survey for recent 10 years, the prevalence of $\mathrm{AD}$ is estimated to be about 50 out of 1,000 people, and its prevalence rate is high in children. In particular, the treatment prognosis and satisfaction of patients have been increasing through personalized treatment in recent years, and accurate diagnosis of $\mathrm{AD}$ is becoming important. This is because the cause of the onset and the mechanism of the symptom can be identified through accurate and detailed diagnosis, which, as a result, provides information that allows the medical staff to perform the treatment specifically for each patient (Eichenfield et al., 2014). In addition, rather than being limited to $\mathrm{AD}$, there is a growing interest in the development of accurate and easy-to-use diagnostic methods for the diagnosis of various diseases, but more than $70 \%$ of the diagnostic kit market around the world is captured by North America and Europe, and more than $80 \%$ of in vitro diagnostic products depend on imports in Korea. Among them, the diagnostic kit related to AD is very scarce in Korea and has potential industrial value. Due to the rapidly changing

Received: January 28, 2019 / Revised: March 3, 2019 / Accepted: March 14, 2019

*Professor.

†Corresponding author: Jeong Hyun Chang. Department of Clinical Laboratory Science, Daegu Haany University, Gyeongsan-si 38610, Korea. Tel: +82-53-819-1350, Fax: +82-53-819-1353, e-mail: jhchang@dhu.ac.kr

(C) The Korean Society for Biomedical Laboratory Sciences. All rights reserved.

(C) This is an Open Access article distributed under the terms of the Creative Commons Attribution Non-Commercial License (http://creativecommons.org/licenses/by-nc/3.0/) which permits unrestricted non-commercial use, distribution, and reproduction in any medium, provided the original work is properly cited. 
science technology, it is also expected that disease-specific biomarkers and antibody development related technology will lead to rapid growth of the market.

Currently, the methods used to diagnose AD in Korea include a skin prick test to check skin reaction after injecting various allergens into the skin for a certain time, urine test, intradermal test, and most of them are IgE test to collect blood and detect total IgE and allergen-specific $\operatorname{IgE}$ in blood. In particular, methods for detecting IgE include radioallergosrobent test (RAST), multiple allergen simultaneous test (MAST), and UniCAP (ImmunoCAP: Phadia/ThermoFisher, USA) systems. However, these tests cause patients to feel pain and discomfort by directly treating the allergen into the patient's body or taking blood. Therefore, it is considered necessary to collect the specimens in a noninvasive manner and to analyze the direct cause of the change of the skin, which is the lesion site, through the specimens (Salkie, 1994; Pastore et al., 2000; Boguniewicz et al., 2006; Liu et al., 2011).

The normal human skin has proteins that constitute a skin barrier, among which filaggrin, loricrin, and involucrin are the most known. However, AD patients may develop atopic dermatitis as skin barrier is weakened congenitally due to gene mutations in one or more of these skin barrier proteins or the expression levels of these proteins have decreased since birth, so it is also important to identify the expression levels of these proteins (O'Regan et al., 2008; Cork et al., 2009). In addition, identification of genes or enzymes directly related to the expression level of the skin barrier protein may be important to provide patient-customized diagnosis and treatment. As mentioned above, however, most atopic dermatitis diagnosis biomarkers are limited to allergen-specific IgE. Therefore, it is necessary to clarify the specific cause and further to understand the mechanism of disease progression and apply it to the patient-customized treatment. The current biomarker research for the diagnosis of atopic dermatitis is proceeding toward protein-based technology, but the development of such protein-based technology is still insufficient compared with advanced countries.

The purpose of this study is to check the protein-based pathogenesis, including skin barrier proteins and enzyme proteins, that constitute the skin of AD patients and to pro- vide a preliminary data for using this as a biomarker for the diagnosis of atopic dermatitis. Another purpose of this study is to make non-invasive diagnosis without blood gathering or tissue biopsy because keratinocytes that can be collected from the epidermis of the skin are used and the biomarker expressed in the cells is targeted.

\section{MATERIALS AND METHODS}

\section{Cell line and cell culture}

As human keratinocyte cell line, HaCaT cells (American Type Culture Collection, Rockville, MD, USA) were suspended in DMEM medium (Sigma-Aldrich, St. Louis, MO, USA) containing 10\% FBS (Life Technologies Inc., Gaithersburg, MD, USA), penicillin (100 U/mL)/streptomycin $(100 \mu \mathrm{g} / \mathrm{mL})$ (Sigma-Aldrich, St. Louis, MO, USA) and cultured at $37^{\circ} \mathrm{C}$ in a $5 \% \mathrm{CO}_{2}$ incubator.

\section{Cell viability assay}

The cell suspension and trypan blue solution (SigmaAldrich, St. Louis, MO, USA) were diluted in the same volume and cells were counted in a hemocytometer (Neubaur type). Regarding cells not stained with the trypan blue solution as living cells and cells stained with the trypan blue solution as dead cells, we determined the ratio of the number of living cells in total number of cells as the cell survival rate.

\section{Cell proliferation assay}

MTT assay was carried out to check whether the stimulators treated in cells are involved in cell proliferation and survival. MTT assay was conducted with cell proliferation kit (Roche, Penzberg, Germany). HaCaT cells were seeded in a 96-well culture plate and treated with an inflammatory substance. After 24 hours, $10 \mu \mathrm{L}$ of MTT reagent was added to each well. After left at $37^{\circ} \mathrm{C}$ for 4 hours, $100 \mu \mathrm{L}$ of the solubilization solution was added to each well. After 24 hours, the absorbance was measured at $550 \mathrm{~nm}$ using an ELISA reader (Bio-Tek Instruments, Winooski, VT).

\section{Enzyme-linked immunosorbent assay (ELISA)}

Sandwich ELISA using OptEIA ${ }^{\mathrm{TM}}$ set human IL-5, IL-1 $\beta$, 
TNF- $\alpha$, MCP-1 (BD bioscience, San Jose, CA, USA) was used to measure protein concentrations from the cell culture supernatants. And USCN (TX, USA) product was used for Kallikrein protease. The experiment was conducted according to the manufacturer's instructions, and all experiments were carried out in triplicate. The concentration of each protein was measured using a standard curve.

\section{RT-PCR}

In order to check the expression of the intracellular skin barrier protein, the cells were lysed to obtain an RNA sample and reverse transcription-polymerase chain reaction (RTPCR) was performed. The types of skin barrier protein identified at this time include filaggrin, loricrin, and involucrin. Total RNA was isolated from HaCaT cells using Trizol ${ }^{\circledR}$ reagent according to the manufacturer's instructions. Complementary DNA (cDNA) was synthesized by reverse transcription with $2 \mu \mathrm{g}$ of total RNA, $0.25 \mu \mathrm{g}$ of random hexamer (Invitrogen) and 200 unit of Moloney murine leukemia virus reverse transcriptase (MMLV-RT; Invitrogen) for $10 \mathrm{~min}$ at $25^{\circ} \mathrm{C}, 50 \mathrm{~min}$ at $37^{\circ} \mathrm{C}$ and $15 \mathrm{~min}$ at $70^{\circ} \mathrm{C}$. cDNA was PCR amplified using Prime Taq premix PCR kit (Genet Bio, Chungnam, Korea) for 25 50 cycles using specific primers. Primer sequences are as follows (Meng et al., 2018): h-FLG (filaggrin); 5'-GGC ACT GAA AGG CAA AAA GG-3' (forword), 5'-AAA CCC GGA TTC ACC ATA ATC A-3' (reverse), h-IVL (involucrin); 5'-CCA TCA GGA GCA AAT GAA ACA G-3' (forword), 5'-GCT CGA CAG GCA CCT TCT G-3' (reverse), h-LOR (loricrin); 5'-ACG TCT CCT CGC AGC AGG-3' (forword), 5'-CTA TTT GGA CGG CCA GGT-3' (reverse), h- $\beta$-actin; 5'-AAC TAC CTT CAA CTC CAT CA-3' (forword), 5'-GAG CAA TGA TCT TGA TCT TCA-3' (reverse).

After RT-PCR, 2\% agarose gel electrophoresis was performed to measure the expression level and Gel images were taken using Gel Doc ${ }^{\mathrm{TM}} \mathrm{XR}+$ system (Bio-Rad, Hercules, CA, USA). Normalization was performed with $\beta$-actin, a house keeping gene, to quantify this and the density of each gene was measured.

\section{Statistical processing}

All results were expressed as means \pm SD. Student's $t$ test was performed using SPSS statistical software package, version 10.0 (SPSS Inc., Chicago, USA) to identify statistical significance. $P$ value $<0.05$ was considered statistically significant.

\section{RESULTS}

\section{Treatment of AD-related inflammation inducers of HaCaT cells}

IL-4 and IL-13 are highly expressed in lesions of patients with atopic dermatitis (Di et al., 2016). Therefore, IL-4 and IL-13 can be used to induce a state similar to keratinocytes found in atopic dermatitis in $\mathrm{HaCaT}$ cells, which are keratinocytes (Omori-Miyake et al., 2014). Thus, in this study, IL-4 and IL-13 were also treated together in HaCaT cells to identify $\mathrm{AD}$ induction in $\mathrm{HaCaT}$ cells and changes in cell viability and proliferation were observed. As a result, there was no difference between the control group treated with nothing and all the experimental groups treated with IL-4 and IL-13 (10, 25, $50 \mathrm{ng} / \mathrm{mL})$ in cell survival rate (Fig. 1) and cell proliferation rate (Fig. 2). This means that the induction of atopic dermatitis in keratinocytes is not related to cell survival and proliferation.

Checking the expression amount of atopic dermatitisrelated pro-inflammatory cytokine in $\mathrm{HaCaT}$ cells

IL-5, IL-6, IL-8, and MCP-1 were identified by ELISA. Atopic dermatitis-related inflammatory responses were well induced by IL-4 and IL-13 in HaCaT cells. IL-4 and IL-13 was treated in a dose-dependent manner, and IL-5, IL-6, and MCP-1 rapidly increased dose-dependently, but there was no significant change in IL-8 levels (Fig. 3).

\section{Checking skin barrier protein expression amount in HaCaT cells}

The inflammation of skin, the lesion site of $\mathrm{AD}$, reduces the expression of proteins that maintain skin barrier (Boguniewicz and Leung, 2011). Therefore, HaCaT cells were treated with IL-4 and IL-13 (50 ng/mL) and then, the expression levels of filaggrin, loricrin, and involucrin, typical skin barrier proteins, were checked by RT-PCR. As a result, it was found that RNA of filaggrin was significantly reduced 


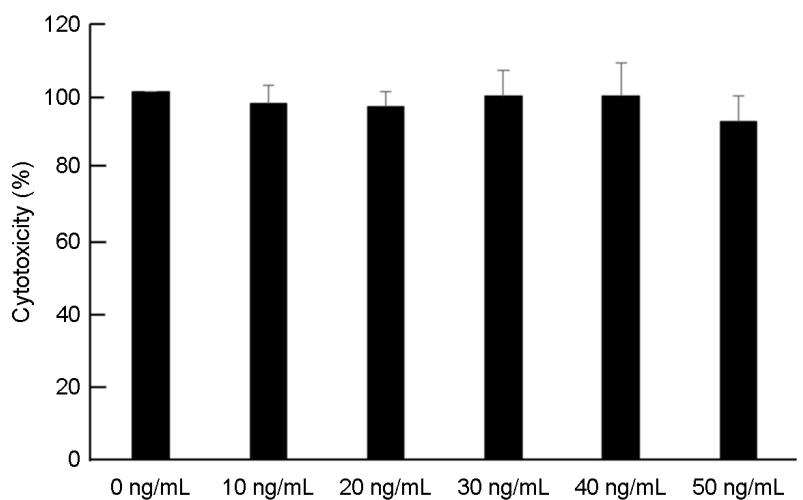

Fig. 1. The cytotoxicity of IL-4 and IL-13 on HaCaT cells. $\mathrm{HaCaT}$ cells were incubated for $24 \mathrm{~h}$ in the absence and presence of IL-4 and IL-13 $(0 \sim 50 \mathrm{ng} / \mathrm{mL})$. The cytotoxicity of IL-4 and IL-13 on the cells was measured by trypan blue stain. The data are expressed as the relative ratio to the cell viability of the untreated cell $(0 \mathrm{ng} / \mathrm{mL})$, which was set at $100 \%$. All data are expressed as the means \pm SD in three individual experiments.
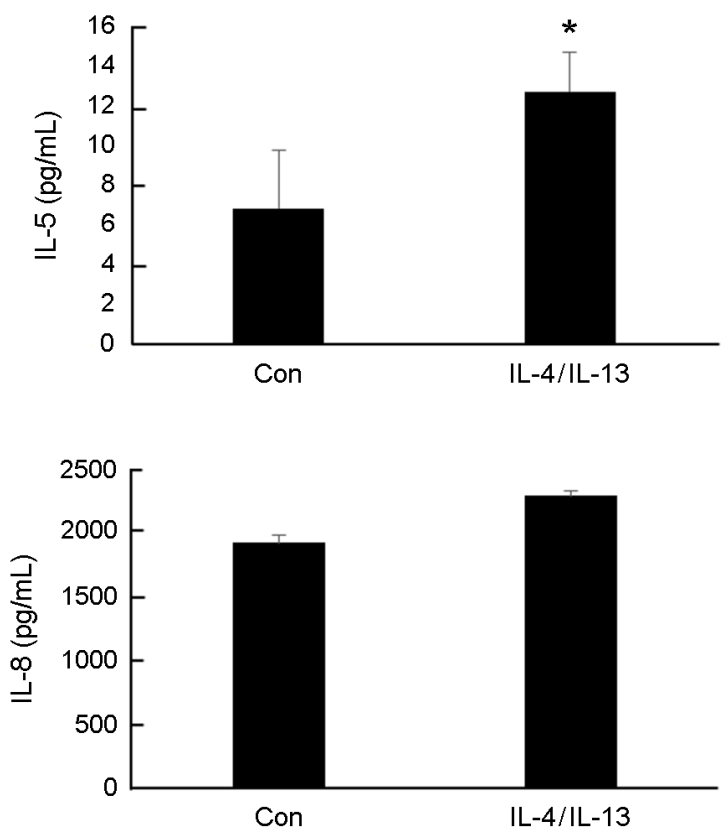

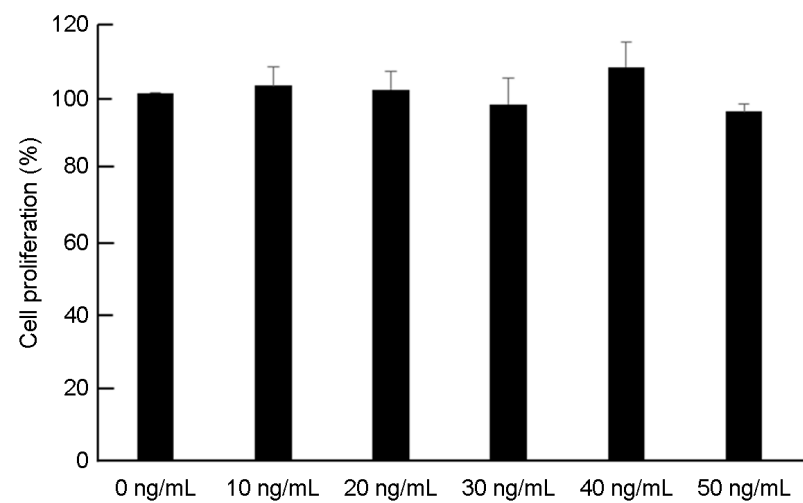

Fig. 2. The effect of IL-4 and IL-13 on the proliferation of HaCaT cells. $\mathrm{HaCaT}$ cells were incubated for $24 \mathrm{~h}$ in the absence and presence of IL-4 and IL-13 $(0 \sim 50 \mathrm{ng} / \mathrm{mL})$. The proliferation of $\mathrm{HaCaT}$ cells was measured by performing MTT assay. The data are expressed as the relative ratio to the cell viability of the untreated cell $(0 \mathrm{ng} / \mathrm{mL})$, which was set at $100 \%$. All data are expressed as the means \pm SD in three individual experiments.
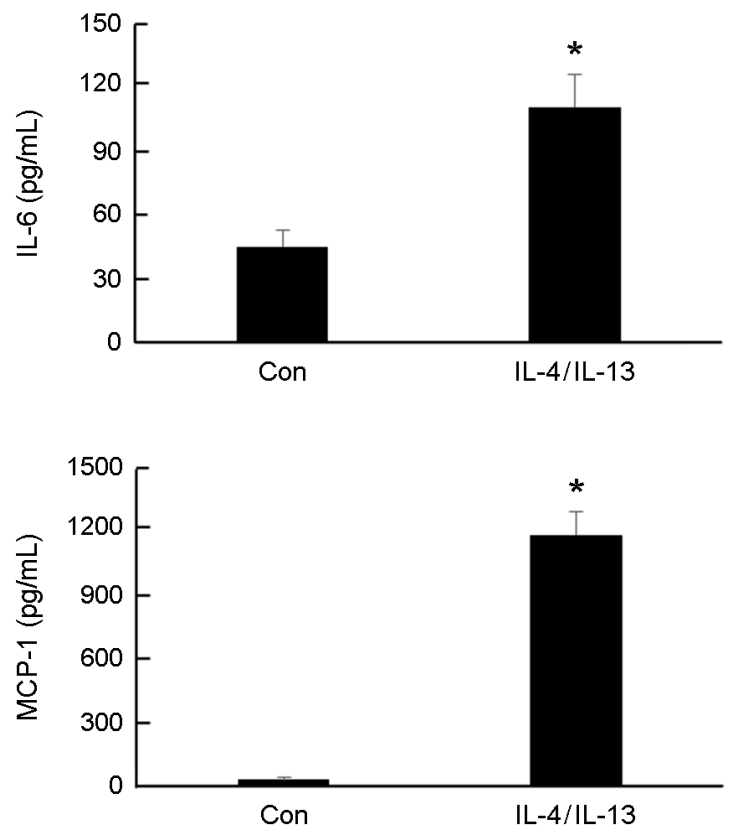

Fig. 3. The effect of IL-4 and IL-13 on the cytokine release of HaCaT cells. HaCaT cells were incubated for $24 \mathrm{~h}$ in the absence (Con) and presence of IL-4 and IL-13 (IL-4/IL-13) $(50 \mathrm{ng} / \mathrm{mL})$. After treatment, the cell culture-supernatants of HaCaT cells were collected and cytokine level (IL-5, IL-6, IL-8 and MCP-1) were analyzed by ELISA. All data are expressed as the means \pm SD in three individual experiments. $* P<0.05$ indicates a significant difference between the untreated cells and the IL-4/IL-13-treated cells.

by IL-4 and IL-13 (Fig. 4).

\section{Checking Kallikrein protease secretion in HaCaT cells}

If the expression of the skin barrier protein such as filag- grin is not due to a genetic defect in AD patients, the skin barrier protein is decreased for various reasons and the symptoms are further aggravated, and protease acts at this time. Thus, the extracellular secretion of kallikrein 5 (KLK5) 

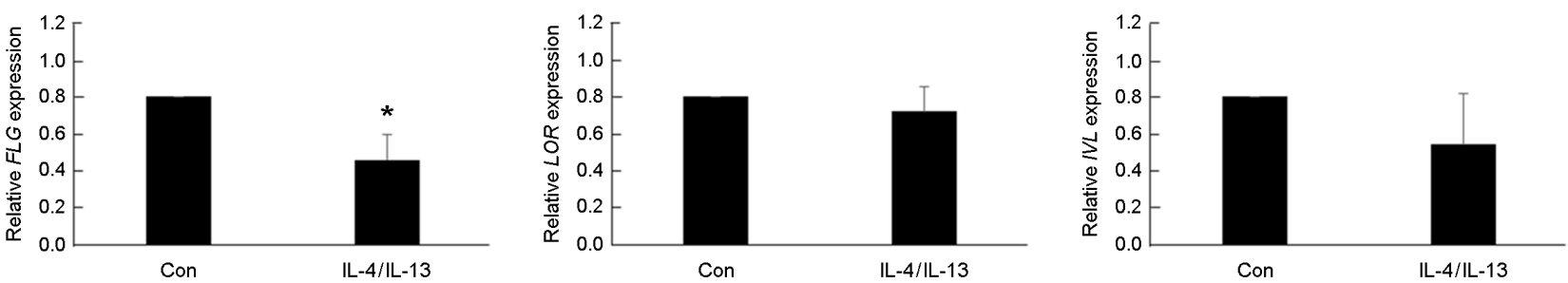

Fig. 4. mRNA expression of skin barrier proteins in IL-4/IL-13-treated HaCaT cells. HaCaT cells were incubated for $24 \mathrm{~h}$ in the absence (Con) and presence of IL-4 and IL-13 (IL-4/IL-13) (50 ng/mL). After treatment, total mRNA was extracted from HaCaT cells. mRNA expression (filaggrin; FLG, loricrin; LOR, involucrin: IVL) of skin barrier proteins was analyzed by RT-PCR. $\beta$-actin was used as an internal control. The data are expressed as the relative ratio to Con. All data are expressed as the means \pm SD in three individual experiments. $* P<0.05$ indicates a significant difference between the untreated cells and the IL-4/IL-13-treated cells.
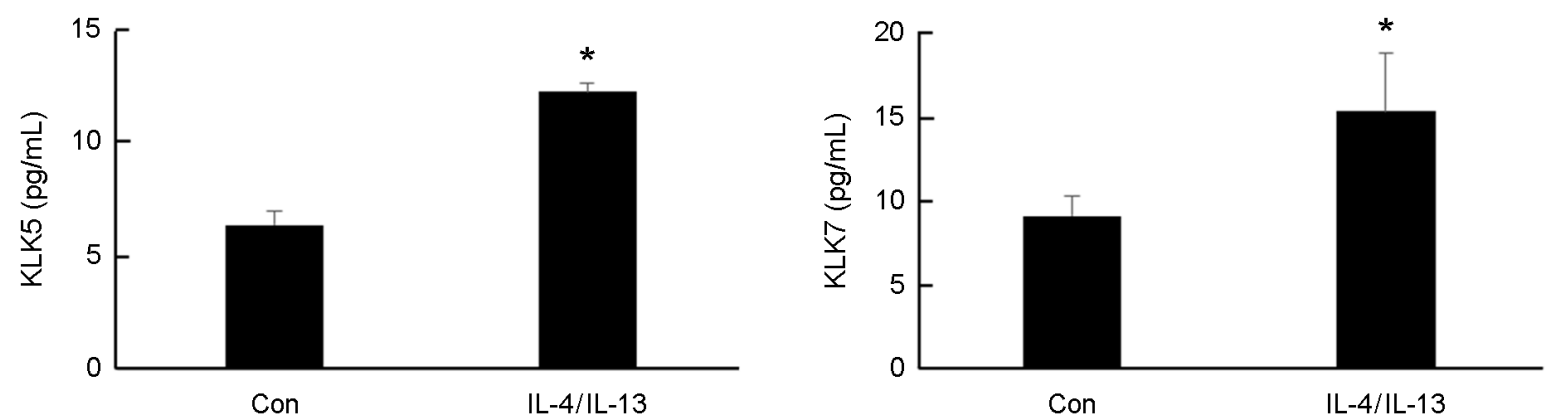

Fig. 5. The effect of IL-4 and IL-13 on the production of kallikrein proteases in HaCaT cells. HaCaT cells were incubated for $24 \mathrm{~h}$ in the absence (Con) and presence of IL-4 and IL-13 (IL-4/IL-13) $(50 \mathrm{ng} / \mathrm{mL})$. After treatment, the cell culture-supernatants of HaCaT cells were collected and kallikrein protease level (KLK5 and KLK7) were analyzed by ELISA. All data are expressed as the means \pm SD in three individual experiments. ${ }^{*} P<0.05$ indicates a significant difference between the untreated cells and the IL-4/IL-13-treated cells.

and kallikrein 7 (KLK7) was identified by ELISA to check whether the expression of atopic dermatitis-related protease was increased in $\mathrm{HaCaT}$ cells. As a result, expression of KLK5 and KLK7 was statistically significantly increased by IL-4 and IL-13 (50 ng/mL) (Fig. 5).

\section{DISCUSSION}

Atopic dermatitis (AD) is a chronic inflammatory disease of the skin which is difficult to treat and some of which may lead to asthma or other allergic diseases (Leung et al., 2004). The prevalence of patients is increasing worldwide, especially in children, and adult and children are slightly different in terms of cause, pathogenesis and treatment approach. Therefore, the development of biomarkers that reflects the individual's disease characteristics is necessary for diagnosis and treatment of $\mathrm{AD}$. In order to diagnose pediatric patients with high prevalence rate, it is important to avoid pain and discomfort during the sampling process or checkup process. To this end, it is necessary to develop a non-invasive AD diagnosis method.

First, understanding of the pathogenesis of $\mathrm{AD}$ is important for the development of specific biomarkers. $\mathrm{AD}$ is a disease in which dry skin and severe itching are accompanied and eczema and rash occur repeatedly and is caused by genetic predisposition and environmental predisposition (Boguniewicz and Leung, 2011). In particular, it is caused by the complex action of immune reactions that occur abnormally by allergen and the reactions associated with the skin barrier substance, which is the lesion site. At this time, the action of keratinocyte present in the skin and immune-related cells is important (Kuo et al., 2012). AD is a T helper (Th) cell type 2 disease in which the expression of Th2 cytokines such as IL-4, IL-5, and IL-13 increases and serum total IgE 
and allergen-specific IgE increase (Leung, 1999). In addition, IFN- $\gamma$, which is Th1 cytokine and thymus and activationregulated chemokine (TARC) and macrophage-derived chemokine (MDC), which are CC chemokines, also increase, enhancing Th2 cell action and immune reaction (Shimada et al., 2004). These complex inflammatory responses are involved in $\mathrm{AD}$ pathogenesis, which affect the expression of proteins that constitute skin barrier in keratinocytes (O'Regan et al., 2008; Cork et al., 2009; Boguniewicz and Leung, 2011; Omori-Miyake et al., 2014; Di et al., 2016).

Proteins that constitute the skin barrier increase the proteins including involucrin and loricrin as calcium ions in the keratinocytes increase, and protect the skin against intrusion of external substances by constituting the skin firmly (Ekanayake-Mudiyanselage et al., 1998). In particular, filaggrin is present in the form of profilaggrin in the granular layer of the skin. And then, it is decomposed into filaggrin in the final differentiation process of keratinocytes and coagulates with keratin to make skin barrier tight. After that, at the top of the stratum corneum, filaggrin is decomposed into amino acids, which are decomposed into pyrrolidone carboxylinc acid (PCA) and free amino acids, which are essential for maintaining skin moisture (Seguchi et al., 1996; Sandilands et al., 2009). These proteins show a sharp decline in the keratin of $\mathrm{AD}$ patients, and secondary bacterial infections may occur due to dryness, itching, and collapse of the skin defense system. In this study, HaCaT cells, a keratinocyte line of keratinocytes, were used to identify changes in skin barrier proteins directly related to $\mathrm{AD}$ symptoms and to use them for diagnosis. In particular, keratinocyte is important because it is directly related to the lesion of $\mathrm{AD}$, but located on the outermost side of the skin, it is differentiated into corneocyte, the final stage of differentiation, and falls off from the skin. Therefore, it is a cell suitable for use as a non-invasive diagnostic specimen because it can be taken from the epidermis without going through any special process without any pain. Therefore, $\mathrm{HaCaT}$ cells were used because the ultimate purpose of this paper is to find biomarkers that can specifically diagnose $\mathrm{AD}$ from the specimen by taking a specimen in a non-invasive manner, and $\mathrm{HaCaT}$ cells were treated with $50 \mathrm{ng} / \mathrm{mL}$ of IL-4 and IL-13, which are highly expressed in $\mathrm{AD}$ patients, for 24 hours in order to make a state similar to $\mathrm{AD}$ patients. This is one of the methods used to stimulate $\mathrm{HaCaT}$ cells in existing studies (Omori-Miyake et al., 2014; Di et al., 2016). As a result, the secretion of cytokines such as IL-5, IL-6 and MCP-1 rapidly increased in $\mathrm{HaCaT}$ cells without cytotoxicity (Fig. 1, Fig. 2, Fig. 3). In addition, filaggrin in $\mathrm{HaCaT}$ cells were significantly reduced (Fig. 4). Although there was no statistical significance, loricrin and Involucrin in HaCaT cells were slightly reduced (Fig. 4). This shows that treatment with IL-4 and IL-13 induced $\mathrm{HaCaT}$ cells to a state similar to keratinocyte in $\mathrm{AD}$ patients. However, these cytokines and chemokines are not sufficient for use as diagnostic markers because they tend to increase not only in AD but also in various inflammatory diseases. And it is judged that they are not suitable for use as a quick diagnostic marker because protein such as filaggrin should be detected directly by protein detection methods such as Western blot. In order to overcome these problems, we focused on protease, which induces changes of epidermal cells including skin barrier proteins.

Proteases involved in skin changes include serine protease containing channel-activating serine protease1 (CAP1), Kallikrein (KLK) 5, KLK7, matriptase, cysteine protease caspase14, and there is Lymphoepithelial Kazal-type-related inhibitor (LEKTI), a protease inhibitor controlling it (Meyer-Hoffert, 2009; Ovaere et al., 2009; Bennett et al., 2010). Protease and protease inhibitor should maintain proper balance to maintain the expression and decomposition of skin barrier proteins constantly, but excessive protease activity degrades skin barrier proteins and makes $\mathrm{AD}$ more severe. In particular, KLK5 and KLK7 are associated with acute skin damage in AD patients (Komatsu et al., 2005; Komatsu et al., 2007). Thus, in order to determine whether the increase of KLK5 and KLK7 in skin keratinocytes is worth applying to the diagnosis of $\mathrm{AD}$ patients, we identified the secretion of expressed proteins, not gene levels, in $\mathrm{HaCaT}$ cells. As a result, it was found that KLK5 and KLK7 were significantly increased in HaCaT cells treated with IL-4 / IL-13 (Fig. 5). This showed that AD-related protease can be detected at the protein level using keratinocytes that can be taken in a noninvasive manner and suggested the possibility of applying it to $\mathrm{AD}$ diagnosis. However, atopic dermatitis is difficult to diagnose at once with a specific test. It is usually diagnosed 
as atopic dermatitis after checking the family history, itching, and form/lesion site of dermatitis. To support this diagnosis, total or allergen-specific IgE of Blood and the skin click test to each allergen are mainly used. IgE and skin prick test are somewhat specific because they have a positive rate of $80 \%$ in $\mathrm{AD}$ patients. On the other hand, cytokine, protease, and skin barrier protein induced by allergen-induced cell stimulation in the atopic response are closely related to atopic dermatitis, but it is a little insufficient for a final confirmation. Therefore, the KLK5 and KLK7 assay confirmed by this study is more suitable as a noninvasive and specific screening test in the diagnosis of atopic dermatitis. In our further study, additional research is needed to develop more specific noninvasive tests.

Nevertheless, these results show that AD-related proteases can be detected from the lesion cells of AD patients at the protein level, and the ELISA used in this study has high specificity and sensitivity in diagnostic tests and can be implemented by automated equipment, which shows that it is can be applied to future $\mathrm{AD}$ diagnosis. In addition, the use of keratinocytes that can be sampled by a non-invasive method to directly identify changes in detectable substances will contribute to the development of diagnostic methods that can be more conveniently applied to the increasing pediatric patients.

\section{ACKNOWLEDGEMENT}

None.

\section{CONFLICT OF INTEREST}

No potential conflict of interest relevant to this article was reported.

\section{REFERENCES}

Bennett K, Callard R, Heywood W, Harper J, Jayakumar A, Clayman GL, Di WL, Mills K. New role for LEKTI in skin barrier formation: label-free quantitative proteomic identification of caspase 14 as a novel target for the protease inhibitor LEKTI. Journal of Proteome Research. 2010. 9: 4289-4294.

Boguniewicz M, Leung DY. Atopic dermatitis: a disease of altered skin barrier and immune dysregulation. Immunological Reviews.
2011. 242: 233-246.

Boguniewicz M, Schmid-Grendelmeier P, Leung DY. Atopic dermatitis. Journal of Allergy and Clinical Immunology. 2006. 118: 40-43.

Cork MJ, Danby SG, Vasilopoulos Y, Hadgraft J, Lane ME, Moustafa M, Guy RH, Macgowan AL, Tazi-Ahnini R, Ward SJ. Epidermal barrier dysfunction in atopic dermatitis. Journal of Investigative Dermatology. 2009. 129: 1892-1908.

Di ZH, Ma L, Qi RQ, Sun XD, Huo W, Zhang L, Lyu YN, Hong YX, Chen HD, Gao XH. T Helper 1 and T Helper 2 Cytokines Differentially Modulate Expression of Filaggrin and its Processing Proteases in Human Keratinocytes. Chinese Medical Journal. 2016. 129: 295-303.

Eichenfield LF, Tom WL, Chamlin SL, Feldman SR, Hanifin JM, Simpson EL, Berger TG, Bergman JN, Cohen DE, Cooper KD, Cordoro KM, Davis DM, Krol A, Margolis DJ, Paller AS, Schwarzenberger K, Silverman RA, Williams HC, Elmets CA, Block J, Harrod CG, Smith Begolka W, Sidbury R. Guidelines of care for the management of atopic dermatitis: section 1. Diagnosis and assessment of atopic dermatitis. Journal of the American Academy of Dermatology. 2014. 70: 338-351.

Ekanayake-Mudiyanselage S, Aschauer H, Schmook FP, Jensen JM, Meingassner JG, Proksch E. Expression of epidermal keratins and the cornified envelope protein involucrin is influenced by permeability barrier disruption. Journal of Investigative Dermatology. 1998. 111: 517-523.

Komatsu N, Saijoh K, Kuk C, Liu AC, Khan S, Shirasaki F, Takehara K, Diamandis EP. Human tissue kallikrein expression in the stratum corneum and serum of atopic dermatitis patients. Experimental Dermatology. 2007. 16: 513-519.

Komatsu N, Saijoh K, Toyama T, Ohka R, Otsuki N, Hussack G, Takehara K, Diamandis EP. Multiple tissue kallikrein mRNA and protein expression in normal skin and skin diseases. British Journal of Dermatology. 2005. 153: 274-281.

Kuo IH, Yoshida T, De Benedetto A, Beck LA. The cutaneous innate immune response in patients with atopic dermatitis. Journal of Allergy and Clinical Immunology. 2013. 131: 266 -278 .

Leung DY, Boguniewicz M, Howell MD, Nomura I, Hamid QA. New insights into atopic dermatitis. Journal of Clinical Investigation. 2004. 113: 651-657.

Leung DY. Pathogenesis of atopic dermatitis. Journal of Allergy and Clinical Immunology. 1999. 104: S99-108.

Liu FT, Goodarzi H, Chen HY. IgE, mast cells, and eosinophils in 
atopic dermatitis. Clinical Reviews in Allergy \& Immunology. 2011. 41: 298-310.

Meng X, Qiu L, Song H, Dang N. MAPK Pathway Involved in Epidermal Terminal Differentiation of Normal Human Epidermal Keratinocytes. Open Medicine. 2018. 10: 189-195.

Meyer-Hoffert U. Reddish, scaly, and itchy: how proteases and their inhibitors contribute to inflammatory skin diseases. Archivum Immunologiae et Therapia Experimentalis. 2009. 57: 345-354.

Omori-Miyake M, Yamashita M, Tsunemi Y, Kawashima M, Yagi J. In vitro assessment of IL-4- or IL-13-mediated changes in the structural components of keratinocytes in mice and humans. Journal of Investigative Dermatology. 2014. 134: 1342-1350.

O'Regan GM, Sandilands A, McLean WHI, Irvine AD. Filaggrin in atopic dermatitis. Journal of Allergy and Clinical Immunology. 2008. 122: 689-693.

Ovaere P, Lippens S, Vandenabeele P, Declercq W. The emerging roles of serine protease cascades in the epidermis. Trends in Biochemical Sciences. 2009. 34: 453-463.

Pastore S, Mascia F, Giustizieri ML, Giannetti A, Girolomoni G. Pathogenetic mechanisms of atopic dermatitis. Archivum
Immunologiae et Therapia Experimentalis. 2000. 48: 497-504.

Salkie ML. Role of clinical laboratory in allergy testing. Clinical Biochemistry. 1994. 27: 343-355.

Sandilands A, Sutherland C, Irvine AD, McLean WH. Filaggrin in the frontline: role in skin barrier function and disease. Journal of Cell Science. 2009. 122: 1285-1294.

Seguchi T, Cui CY, Kusuda S, Takahashi M, Aisu K, Tezuka T. Decreased expression of filaggrin in atopic skin. Archives of Dermatological Research. 1996. 288: 442-446.

Shimada Y, Takehara K, Sato S. Both Th2 and Th1 chemokines (TARC/CCL17, MDC/CCL22, and Mig/CXCL9) are elevated in sera from patients with atopic dermatitis. Journal of Dermatological Science. 2004. 34: 201-208.

https://doi.org/10.15616/BSL.2019.25.1.15

Cite this article as: Chang JH. Noninvasive Detection of Specific Diagnostic Biomarkers for Atopic Dermatitis. Biomedical Science Letters. 2019. 25: 15-22. 